\title{
Stress random distributions on railway subgrade surface under train loads considering irregular shapes of ballast
}

\author{
J. Xiao \\ Shanghai Key Laboratory of Rail Infrastructure Durability and System Safety \& Key Laboratory of Road \\ and Traffic Engineering of the Ministry of Education, Tongji University, Shanghai, China \\ L. Xue \\ Key Laboratory of Road and Traffic Engineering of the Ministry of Education, Tongji University, Shanghai, \\ China \\ P. Jing \\ College of Metropolitan Transportation, Beijing University of Technology, Beijing, China \\ D. Zhang \\ Shanghai Road and Bridge (Group) Co. Ltd, Shanghai, China
}

\begin{abstract}
The morphological features of railway ballast, especially the edges and corners, have a great impact on the additional stress on the subgrade surface induced by train loads. In this paper, a novel shape reconstruction method was adopted to generate an arbitrary number of ballast particles. Then, a three-dimensional Discrete element-Finite element method (DEM-FEM) coupling model of the ballasted track-subgrade, in which the ballasted track was simulated by DEM and the subgrade soil was simulated by FEM, was established to analyze the contact stress at the ballast-subgrade interface. In this work, 150 groups of ballasted track-subgrade numerical models composed of irregular particles with randomly reconstructed shapes were applied to investigate the stress distributions on the subgrade surface under various train axle loads. Besides, the average stress of a $10 \mathrm{~cm}$ diameter circular area on the subgrade surface directly under the wheel load was calculated. The results indicated that both the peak and average additional stresses induced by train loads followed normal distributions for various numerical models (i.e., various groups of random ballast particle morphology). Compared with field testing data of the additional stress on the subgrade surface under train loads acquired by earth pressure cell, the larger average stresses were obtained in numerical models, because of direct contact between ballast particles and the subgrade along with stress homogenization by the pressure cell.
\end{abstract}

Keywords: Ballasted track, additional stress on subgrade stress, ballast shape, DEM-FEM coupling model, stress random distribution

\section{INTRODUCTION}

Fine-grained soil was widely used as fill on the subgrade in Chinese conventional railway, which forms the substructure of direct contact between the ballast and soil 
subgrade. With the growing demand of heavy-haul freight transportation, the loading cycles and subgrade dynamic stress increase. It can result in several kinds of subgrade deterioration during railway operation, posing threats to traffic safety (Xiao et al. 2020). Thus, the research on the characterization of subgrade dynamic response under heavy load condition is of theoretical significance for the reinforcement and maintenance of existing railways.

For the dynamic response inside the subgrade, the calculation method based on Boussinesq solution is widely adopted to obtain the attenuation curves of dynamic stress in the vertical direction (Chen, 2014). Hence, once the dynamic stress distribution on the subgrade surface is determined, the dynamic response of subgrade can be acquired. At present, most research works have revealed that the peak dynamic stress on the subgrade surface shows a saddle-shaped distribution in transverse direction. Relevant research work (Mei et al. 2019) has analyzed the random distribution of the subgrade dynamic stress from the aspects of stiffness change and track irregularity. However, in their studies, the ballast track was taken as the continuum, and the dispersion of stress distribution at ballast-soil interface was ignored.

With the appearance of advanced measurements, such as pressure-sensitive paper (Mchenry et al. 2015) granular material pressure cell (Liu et al. 2017), and tactile sensor (Aikawa, 2009), the contact stress inside the ballast layer was measured. These testing results indicated the angular characteristics of ballast leading to stress concentrations at the sleeper-ballast-soil interfaces. In addition to experimental methods, some scholars established the ballasted track-subgrade model through the Discrete element-Finite element method (DEM-FEM) coupling method to investigate the effect of contact dispersion and particle geometry on mechanical behavior of ballasted track. Three dimensional shapes such as spherical cluster (McDowell and Li 2016), super ellipsoid (Zhao and Zhou 2017) or polyhedron (Huang and Tutumluer 2013) were used to model ballast particles. Nevertheless, most existing reconstruction methods lack statistical analysis on the overall morphological characteristics of real ballast particles. Thus, there are gaps between the reconstructed and real ballast in shape description.

In this paper, a shape reconstruction method was adopted based on the probability density distribution of morphological indices. Through the preparatory work of laser scanning and analysis of ballast particle morphology, 150 groups of ballast samples randomly regenerated, which conform with the morphological characteristics of natural ballast. After that, a three-dimensional DEM-FEM coupling model of ballasted tracksubgrade was established. The average stress of a $10 \mathrm{~cm}$ diameter circular area and peak stress were obtained and forecasted with statistical method. The results indicated that both kinds of stresses obey normal distributions. In comparison with field testing data acquired by earth pressure cell, the larger average stresses were obtained in numerical models.

\section{STATISTICAL ANALYSIS AND RECONSTRUCTION OF BALLAST PARTICLES MORPHOLOGY}

In this paper, point clouds of surface contours of ballast particle samples were obtained by $3 \mathrm{D}$ laser scanning and analyzed to give a quantitative description of the morphological characterization of real ballast particles. Related literature (Noura et al. 2017) has pointed out that when the particle number exceeded 400 , the statistical result of the ballast particles' morphological characterization would tend to be stable. Therefore, a $50 \mathrm{~kg}$ ballast sample containing a total of 584 ballast particles sieved according to the current Chinese code (TB/T 2140-2008) for the first-class gravel ballast, and the grading curve of the ballast sample is presented in Figure 1. 


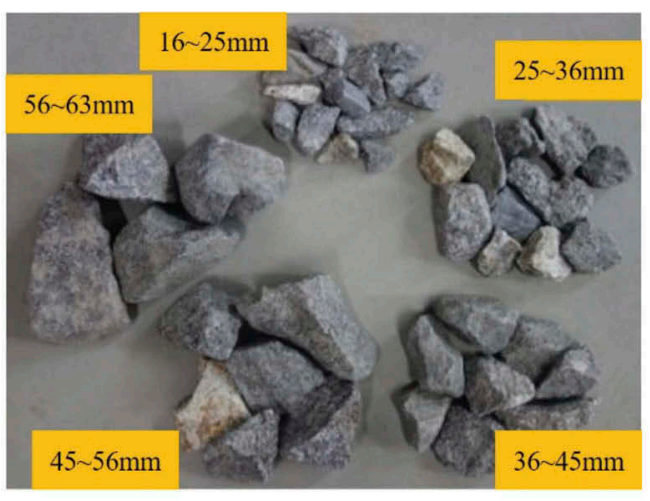

(a) Some selected ballast particles sample

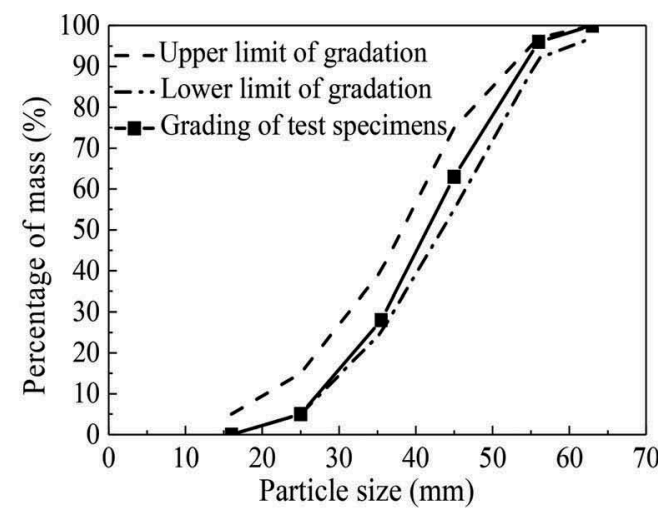

(b) Grading curve of ballast sample

Figure 1. Selection and grading curve of ballast sample.

In general, global and local shape features should be both considered when characterizing particle morphology (Huang and Tutumluer, 2013; Pen, 2013). Global morphological features mainly refer to the basic geometric dimensions and shape, and generally described with long axis $\left(\Phi_{1}\right)$, middle axis $\left(\Phi_{2}\right)$, short axis $\left(\Phi_{3}\right)$ and sphericity index $\left(S p^{3}\right)$ (Yan et al. 2016). $\Phi_{1}$ indicates the distance between the two farthest surface points of the particle. Located on the maximum projection plane perpendicular to $\Phi_{1}, S$, the longest dimension is called $\Phi_{2}$. And $\Phi_{3}$ is the maximum dimension perpendicular to $\Phi_{1}$ and $\Phi_{2}$. The schematic diagram of these three axes is shown in Figure 2.

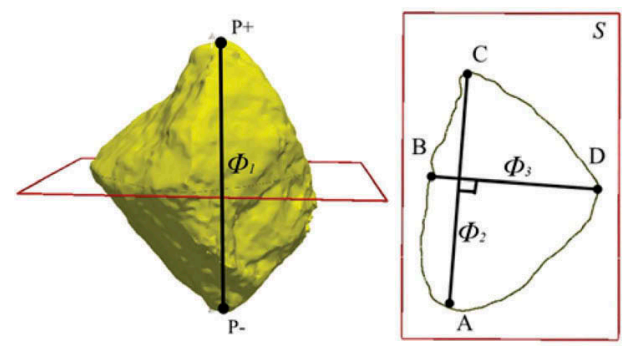

Figure 2. Schematic diagrams of $\Phi_{1}, \Phi_{2}$ and $\Phi_{3}$.

Sphericity index $(S p)$ is defined based on the above three indices, which describes the degree of approximation between an irregular particle and a sphere, and can be solved by following Eq. (1):

$$
S p^{3}=\frac{\Phi_{2} \times \Phi_{3}}{\Phi_{1}^{2}}
$$

Local morphological feature mainly focuses on the edges and angularities on the surface of particles, and in this paper, it was quantified by the curvature index $(C I)$. It is found that at least $20 \%$ of the points are located on the edge or vertex, and the corresponding local curvature is greater than that on the face. Therefore, the sum of the curvature from the first $20 \%$ is taken as the curvature index, as can be written as Eq. (2): 


$$
C I=\sum_{i=1}^{20 \% N} \rho_{i}=\sum_{i=1}^{160} \rho_{i}
$$

where $\rho_{i}$ is the discrete local curvature and is arranged in descending order; $N$ is the number of points in each point cloud, and was normalized to 800 for each particle in this paper.

Then, the above five indices of 584 particles were statistically analyzed and their probability density distributions were calculated. However, because of the large number of original point clouds and high nonlinearity of the morphology indices, we applied the Proper Orthogonal Decomposition (POD) to find dominant eigenvectors for describing the main morphological features of ballast particles, and then took these eigenvectors and corresponding shape expansion coefficients $\left(C_{0}, \ldots, C_{34}\right)$ to reconstruct equivalent particles. After that, the mapping relationship between the shape expansion coefficients and indices of morphological feature was obtained by Radial Basis Function (RBF) Neural Network, so that the specific coefficients could be calculated according to the desired probability distribution of the morphological feature indices. In this way, it's possible to model any number of ballast particles that conform to the desired probability density distribution. The flow chart of ballast regeneration was shown in Figure 3. For this part, more details can be found in the previous literature (Xiao et al. 2020).

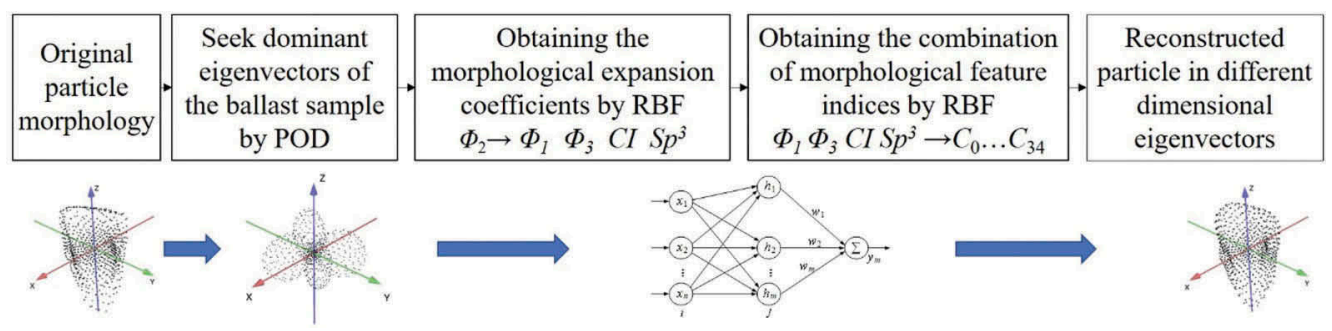

Figure 3. Flow chart of ballast shape regeneration.

\section{BALLASTED TRACK-SUBGRADE MODEL}

In this work, the ballasted track was simulated using DEM, whereas the sleeper and the subgrade soil were modeled by FEM. For the sake of calculation efficiency and accuracy, the surface coupling method was applied to calculate the interaction between two domains. If there are no contact between ballasts and the sleeper, the analysis of DEM and FEM is conducted separately. Once the contact occurs, the FEM interface mesh is copied into the DEM domain as facet elements and the displacement boundary conditions are introduced and the contact forces acting on the facet elements are transferred into FEM domain (Song et al. 2019).

The model size was determined in terms of the current railway track and subgrade design specifications in China. Only half of each structure was modelled along the cross-sectional. Type $\square$ sleeper was used in simulation, with dimensions of $1.25 \mathrm{~m} \times 0.3 \mathrm{~m} \times 0.23 \mathrm{~m}$ (length $\times$ width $\times$ height). The height, upper and lower surface widths of track bed were $0.35 \mathrm{~m}$, $1.5 \mathrm{~m}$ and $2.2 \mathrm{~m}$ respectively. The longitudinal length of track bed and subgrade was $0.6 \mathrm{~m}$. For the widths of the subgrade, the upper and lower surface were $3.05 \mathrm{~m}$ and $4.65 \mathrm{~m}$ separately. In the vertical range, the thickness of the surface layer was $0.6 \mathrm{~m}$, and the bottom layer was $0.4 \mathrm{~m}$. In order to reduce the reflection of stress wave under cyclic loading, viscoelastic damping boundaries with the grid elements (normal stiffness was $1.2 \times 10^{8} \mathrm{~N} / \mathrm{m}$ and damping coefficient was 0.6 ) of $5 \mathrm{~cm}$ thickness were set around the model. The specific dimensions are indicated in Figure 4. 


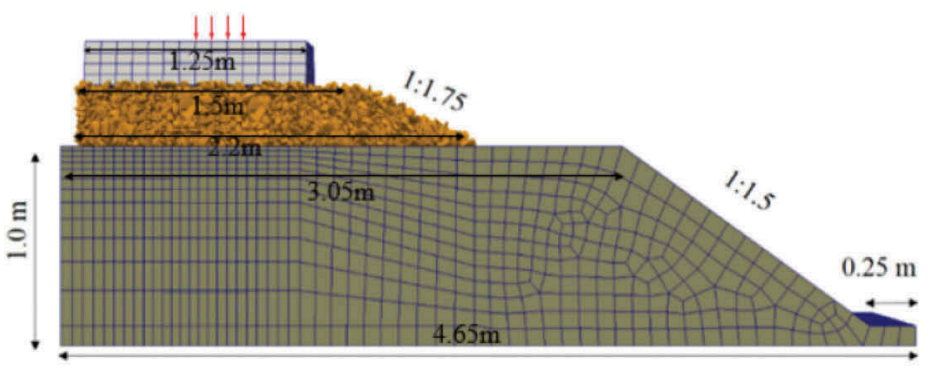

(a) section view

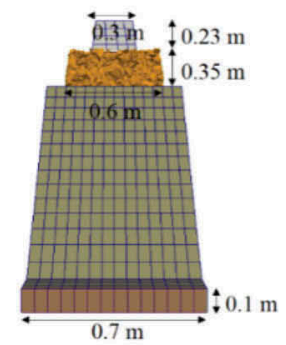

(b) side view

Figure 4. A three-dimensional DEM-FEM coupling model of sleeper-ballasted track-subgrade.

In this work, 150 groups of ballasted track-subgrade numerical models were generated. The number of ballast particles $N_{i}$ in each sample ranged from 7373 to 7590 . Based on the probability density distribution of the morphological feature indices gained by $3 \mathrm{D}$ laser scanning, corresponding index values were obtained in the range of each morphological index with the uniform distribution random number. Adopting the particle shape reconstruction method established above, polyhedral particles were modelled in the discrete element program YADE.

The modeling of the sleeper and subgrade were conducted by open-source code OOFEM (Patzák 2012) as FEM parts. The concrete sleeper was simulated with the linear elastic constitutive model, whereas the Drucker-Prager constitutive model was used for the subgrade. Some parameters used in the DEM-FEM modeling are presented in Table 1.

Table 1. Structural parameters in the DEM-FEM coupling model of the sleeper-ballasted track-subgrade.

\begin{tabular}{|c|c|c|c|c|c|c|c|}
\hline DEM & $\begin{array}{l}\text { Density } \\
\rho /\left(\mathrm{kg} \cdot \mathrm{m}^{-3}\right)\end{array}$ & $\begin{array}{l}\text { Normal } \\
\text { volume } \\
\text { stiffness } \\
\mathrm{k}_{\mathrm{n}} /\left(\mathrm{N} \cdot \mathrm{m}^{-3}\right)\end{array}$ & $\begin{array}{l}\text { Tangential } \\
\text { volume } \\
\text { stiffness } \\
\mathrm{k}_{\mathrm{s}} /\left(\mathrm{N} \cdot \mathrm{m}^{-3}\right)\end{array}$ & $\begin{array}{l}\text { Friction } \\
\text { coefficient }\end{array}$ & $\begin{array}{l}\text { Damping } \\
\text { coefficient }\end{array}$ & \multicolumn{2}{|c|}{ Time step $\Delta \mathrm{t} /\left(\operatorname{step} \cdot \mathrm{s}^{-1}\right)$} \\
\hline Ballast & 2600 & $1.82 \times 10^{1 \circ}$ & $1.6 \times 10^{1 \circ}$ & 0.65 & 0.03 & $1 \times 10^{-6}$ & \\
\hline FEM & $\begin{array}{l}\text { Density } \\
\rho /\left(\mathrm{kg} \cdot \mathrm{m}^{-3}\right)\end{array}$ & $\begin{array}{l}\text { Modulus } \\
\text { E/Pa }\end{array}$ & $\begin{array}{l}\text { Poisson's } \\
\text { ratio } \\
\mu\end{array}$ & $\begin{array}{l}\text { Friction } \\
\text { angle } /^{\circ}\end{array}$ & $\begin{array}{l}\text { Damping } \\
\text { coefficient } \\
\text { c }\end{array}$ & $\begin{array}{l}\text { Cohesion / } \\
\mathrm{kPa}\end{array}$ & $\begin{array}{l}\text { Time } \\
\text { step } \Delta t / \\
\left(\text { step } \cdot s^{-1}\right)\end{array}$ \\
\hline $\begin{array}{l}\text { Sleeper } \\
\text { Surface } \\
\text { layer of } \\
\text { subgrade }\end{array}$ & $\begin{array}{l}2600 \\
1950\end{array}$ & $\begin{array}{l}3.0 \times 10^{10} \\
1.2 \times 10^{8}\end{array}$ & $\begin{array}{l}0.2 \\
0.33\end{array}$ & - & $\begin{array}{l}0.03 \\
0.3\end{array}$ & $\begin{array}{l}- \\
30\end{array}$ & $\begin{array}{l}1 \times 10^{-6} \\
1 \times 10^{-6}\end{array}$ \\
\hline $\begin{array}{l}\text { Bottom } \\
\text { layer of } \\
\text { subgrade }\end{array}$ & 1900 & $6.0 \times 10^{7}$ & 0.35 & 20 & 0.3 & 20 & $1 \times 10^{-6}$ \\
\hline
\end{tabular}

The train load applied on the rail pad, with a length of $0.305 \mathrm{~m}$, as shown in Figure 4 (a). About 5 sleepers bore the single axle load at a ratio of 0.1:0.2:0.4:0.2:0.1. The load magnitude was calculated as 0.4 times the wheel weight. Therefore, the amplitudes under the axle load of $25 \mathrm{t}, 27 \mathrm{t}$ and $30 \mathrm{t}$ were $50 \mathrm{kN}, 54 \mathrm{kN}$ and $60 \mathrm{kN}$ respectively. For the sake of computational cost, the loading frequency was fixed at $1 \mathrm{~Hz}$ and the duration was one cycle of halfsinusoidal wave. 


\section{PROBABILITY ANALYSIS OF DYNAMIC STRESS ON THE SUBGRADE SURFACE}

\subsection{Random characteristics of dynamic stress on the subgrade surface}

The case of the model under $30 \mathrm{t}$ axle load was selected as an example for the following analysis. The distribution of sleeper stress and force chains of ballast particles at the peak of the train load were shown in Figure 5. As can be seen, the distribution of contact stress between the sleeper and ballast was discrete, and stress concentration at the end of the sleeper was induced. The results are consistent with field measurements (Mchenry et al. 2015).

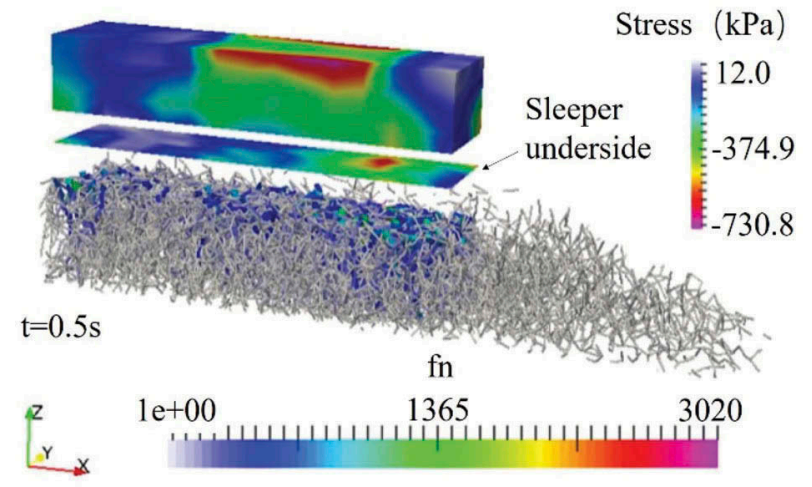

Figure 5. The distribution of sleeper stress and force chains inside ballasted track under $30 \mathrm{t}$ train load.

As illustrated in Figure 5, main force chains were randomly generated inside the ballasted track below the end of the sleeper, which bore the main load and transferred it to the subgrade surface. Within these regions, the interactions between the irregular ballast particles and the subgrade surface were dominated by face-face contact, while in the other areas were edgeface or vertex-face contact. It can be seen that the random formation of the main force chains and the discrete contact at the interface contributes to the random characteristics of dynamic stress on the subgrade surface.

Figure 6 shows the stress nephogram on the subgrade surface under the $30 \mathrm{t}$ axle load, which reveals that, under the loading area, the dynamic stress on the subgrade surface was significantly higher than that at other positions, and the peak dynamic stress was $2165.2 \mathrm{kPa}$. Besides, in the field experiment, the earth pressure cell with diameter no less than $10 \mathrm{~cm}$ is often used to measure the subgrade stress, so the average stress of a $10 \mathrm{~cm}$ diameter area on the subgrade surface directly under the wheel load was calculated (hereinafter referred to as "stress at D10 area"). Under the $30 \mathrm{t}$ axle load, the stress at D10 area was $135.8 \mathrm{kPa}$, far less than the peak dynamic stress on the subgrade surface. Besides, as depicted from 150 groups of test results, under all axle loads, the peak dynamic stresses were found in the area under the sleeper.

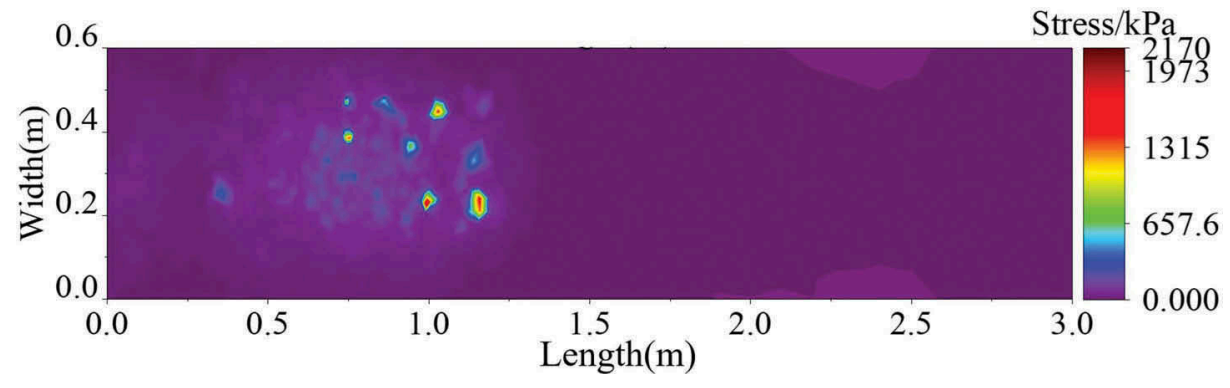

Figure 6. Stress nephograms on the subgrade surface under $30 \mathrm{t}$ train load. 


\subsection{Normality test on peak dynamic stress and stress at D10 area}

For 150 groups of test results, the peak dynamic stress and stress at D10 area on the subgrade surface under different axle loads are depicted in Figure 7.

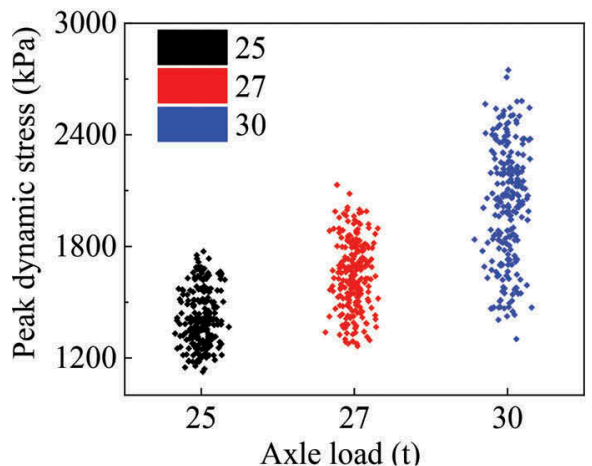

(a) Peak dynamic stress

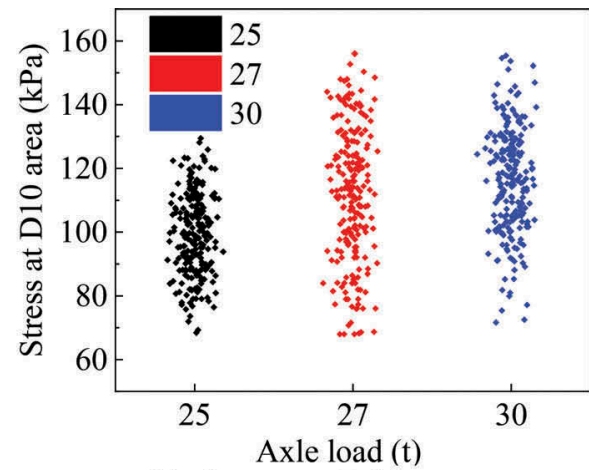

(b) Stress at D10 area

Figure 7. Peak dynamic stress and stress at D10 area on the subgrade surface under different axle load.

It is generally considered that the wheel-load is normally distributed (Chen et al. 2016). In this study, the Kolmogorov test is performed to verify the normal distribution of peak dynamic stress and stress at D10 area on the subgrade surface. The specific steps are as follows (Chen et al. 2016):

Assuming the distribution function of population $X$ is $F(x), F(x)$ is a continuous function but unknown, $(X 1, X 2, \ldots X n)$ is a sample from the population, and $F_{n}(x)$ is a better estimate of $F(x)$. Since $F(x)$ is a nondecreasing function, the following test statistic is constructed:

$$
\begin{gathered}
D_{n}=\max _{0<i<n}\left|F_{n}\left(x_{i}\right)-F_{0}\left(x_{i}\right)\right| \\
F_{n}\left(x_{i}\right)=i / n \\
F_{0}(x)=\Phi\left(\frac{x-\bar{x}}{s^{*}}\right)
\end{gathered}
$$

where $\left(x_{1}, x_{2}, \ldots x_{\mathrm{n}}\right)$ are observation values of order statistics $(X 1, X 2, \ldots X n), \mu$ is the mean of the observation values, $\mu=\bar{x}$, and $\sigma$ is the standard deviation, $\sigma=s^{*}$.

Corresponding to significance level $\alpha$, there exists a critical value $D_{n, \alpha}$. When $D_{n}$ is less than $D_{n, \alpha}, F_{\mathrm{n}}(x)=F_{0}(x)$ can be regarded as true, that is, at the significance level $\alpha$, the population obeys a normal distribution.

The normality analyses of peak dynamic stress and stress at D10 area on the subgrade surface under various axle loads are performed according to the above method. Table 2 lists the $D_{n}$ values at various conditions.

Table 2. Statistical table of the normality test of the peak dynamic stress and stress at D10 area on the subgrade surface.

\begin{tabular}{lllll}
\hline & $\mathrm{D}_{\mathrm{n}}$ & \multicolumn{1}{c}{$\mathrm{D}_{\mathrm{n}, \alpha}$} & \\
\cline { 2 - 5 } Axle load $(\mathrm{t})$ & Peak dynamic stress & Stress at D10 area & $\alpha=0.05$ & $\alpha=0.01$ \\
\hline 25 & 0.048 & 0.033 & 0.058 & 0.069 \\
27 & 0.028 & 0.035 & 0.058 & 0.069 \\
30 & 0.035 & 0.042 & 0.058 & 0.069 \\
\hline
\end{tabular}


It can be seen that $D_{n}$ is less than $D_{n, \alpha}$ at significance levels $\alpha$ of 0.05 and 0.01 . Therefore, the peak dynamic stress and stress at D10 area can be considered to obey the normal distribution. Taking the statistical results of $30 \mathrm{t}$ axle load as an example, the histogram of the peak dynamic stress and stress at D10 area is shown in Figure 8.

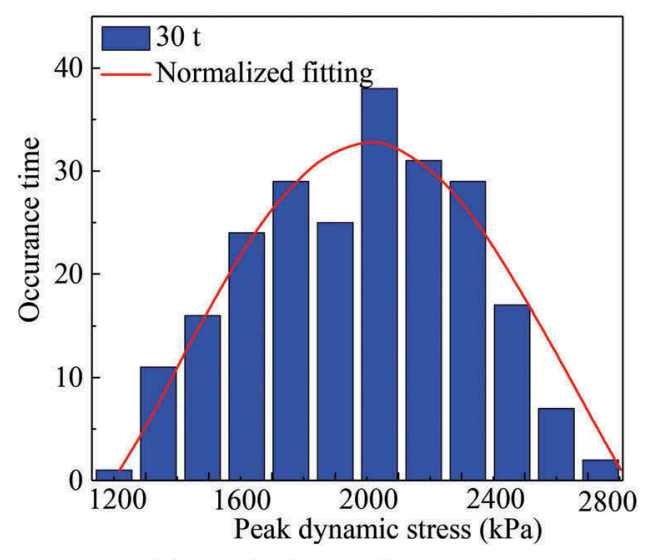

(a) Peak dynamic stress

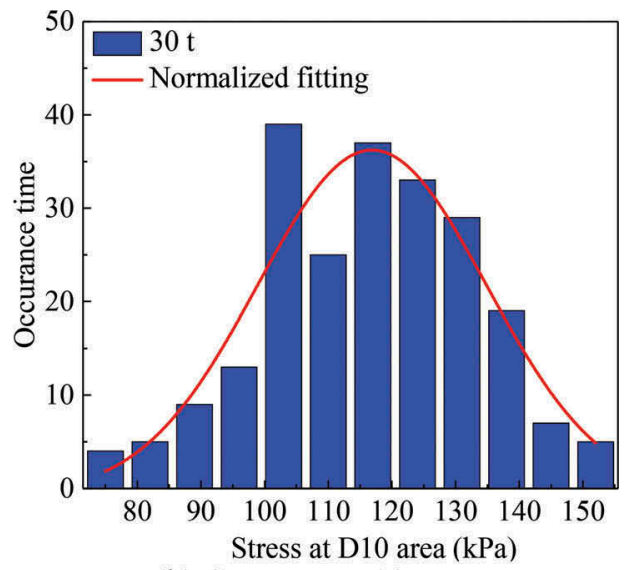

(b) Stress at D10 area

Figure 8. Histogram of peak stress and stress at D10 area under $30 \mathrm{t}$ axle load.

\subsection{Maximum forecast of peak dynamic stress and stress at D10 area}

According to the $3 \sigma$ principle of normal distributions, the interval $(\mu-3 \sigma, \mu+3 \sigma)$ is regarded as the possible range for true values of the population. That is to say, $\mu+3 \sigma$ is the maximum value of peak dynamic stress and stress at D10 area if they obey the normal distribution. Table 3 summarizes the inferred maximum value of the above two stresses under different axle load.

Table 3. Maximum peak dynamic stress and stress at D10 area on the subgrade surface.

\begin{tabular}{llccc}
\hline Axle load $(\mathrm{t})$ & Dynamic stress & Mean $(\mathrm{kPa})$ & Standard deviation $(\mathrm{kPa})$ & Maximum $(\mathrm{kPa})$ \\
\hline 25 & Peak dynamic stress & 1418.35 & 150.61 & 1870.2 \\
& Stress at D10 area & 99.17 & 12.70 & 137.28 \\
27 & Peak dynamic stress & 1648.94 & 190.17 & 2219.45 \\
\multirow{3}{*}{30} & Stress at D10 area & 112.14 & 15.41 & 158.37 \\
& Peak dynamic stress & 2021.79 & 313.64 & 2962.71 \\
& Stress at D10 area & 116.17 & 16.56 & 165.85 \\
\hline
\end{tabular}

To verify the reliability of the probability analysis result, we compared the maximum stress at D10 area, the field test result and the calculation result obtained from the empirical formula (Zhang 2005), as shown in Table 4. 
Table 4. Comparison of probability analysis result, test results and empirical calculations.

\begin{tabular}{lllll}
\hline Analysis method & $\begin{array}{l}\text { Thickness of ballasted } \\
\text { track }(\mathrm{cm})\end{array}$ & $\begin{array}{l}\text { Axle weight } \\
(\mathrm{t})\end{array}$ & $\begin{array}{l}\text { Speed } \\
(\mathrm{km} / \mathrm{h})\end{array}$ & $\begin{array}{l}\text { Dynamic stress } \\
(\mathrm{kPa})\end{array}$ \\
\hline Field test result in Shuo-Huang & 250 & 25 & $<100$ & $93 \sim 110$ \\
railway & & 30 & $<100$ & $100 \sim 123$ \\
Maximum stress at D10 area & 35 & 25 & 120 & 137 \\
& & 30 & 120 & 166 \\
& & 25 & 120 & 104 \\
Empirical calculations result & 35 & 30 & 120 & 125 \\
\hline
\end{tabular}

It can be seen that the maximum value of stress at D10 area inferred from the coupling model results is higher than the test value and empirical calculation value. The main reasons are as follows: (1) In the coupling model calculation, the stress concentration caused by the irregular shapes of ballast particles is considered, while the stress distribution is relatively uniform due to the stiffness of the earth pressure cell; (2) The thickness of ballasted track in the numerical model is smaller than that in the field test, which leads to the different degree of stress diffusion; (3) Particles in the numerical model simulate the clean ballasts with more obvious edges and angularities characteristics, whereas the ballast on the operating railway is fouled and worn, leading to the reduction of the contact stress.

\section{CONCLUSION}

In this paper, a novel shape reconstruction method was adopted to randomly regenerate 150 groups of ballast samples conforming to the statistical regularity of overall morphological characteristics of natural ballast. Based on it, a ballasted track-subgrade coupling model was established to investigate the stress distribution on the subgrade surface under three axle loads. The main conclusions are as follows:

The shape reconstruction method based on the probability density function of morphological indices can ensure that the modeled ballast has the same probability distribution as the real ballast. In addition, increasing the number of particles does not lead to the difference in the probability distribution.

The random formation of the main force chain inside the ballasted track and the discrete contact at the interface caused by the irregular shape of the particles are the major reasons for the random distribution of the dynamic stress on the subgrade surface. The peak dynamic stress was much higher than the stress at D10 area. No matter what the axle load was, the peak dynamic stress occurred under the sleepers.

Both the peak stress and stress at D10 area follow normal distributions. Due to the influence of factors such as ballast fouling, filling thickness and stress homogenization by the pressure cell, the larger average stresses were obtained in numerical models compared with field testing data.

\section{ACKNOWLEDGEMENTS}

This research is supported by the NSFC (National Natural Science Foundation of China) Program Grant NO. 51678447, which is greatly appreciated.

\section{REFERENCES}

Aikawa, A., 2009. Techniques to Measure Effects of Passing Trains on Dynamic Pressure Applied to Sleeper Bottoms and Dynamic Behavior of Ballast Stones. Quarterly Report of Rtri, 50(2): 102-109.

Chen, R., 2014. Recent research on the track-subgrade of high-speed railways. Journal of Zhejiang University, 15(12): 1034-1038. 
Chen, R., Jiang, P., Duan, X., et al, 2016. Probability Distribution of Dynamic Stress of High-speed Subgrade under Slab Track Irregularity. Journal of the China Railway Society, 38 (9).

Huang, H., Tutumluer, E., 2013. Image-Aided Element Shape Generation Method in Discrete-Element Modeling for Railroad Ballast. Journal of Materials in Civil Engineering, 26(3): 527-535.

Liu, Q., Lei, X., Rose. J., et al, 2017. Pressure Measurements at the Tie-Ballast Interface in Railroad Tracks Using Granular Material Pressure Cells: V001T01A003.

Mcdowell, G. and Li, H., 2016. Discrete element modelling of scaled railway ballast under triaxial conditions. Granular Matter, 18(3).

Mchenry, M., Brown, M., Lopresti, J., et al, 2015. Use of Matrix-Based Tactile Surface Sensors to Assess Fine-Scale Ballast-Tie Interface Pressure Distribution in railroad Track. Journal of the Transportation Research Board, 2476(2476): 23-31.

Mei H, Leng W, Nie R, et al, 2019. Random Distribution Characteristics of Peak Dynamic Stress on the Subgrade Surface of Heavy-Haul Railways Considering Track Irregularities. Soil Dynamics and Earthquake Engineering, 116: 205-214.

Noura, O., Charles, V., Guillaume, P., et al, 2017. 3D Particle Shape modelling and optimization through proper orthogonal decomposition application to railway ballast. Granular Matter, 19 (4): 86-1-86-14.

Patz'ak, B., Rypl, D. and Kruis, J, et al, 2012. MuPIF - A Distributed Multi-physics Integration Tool. Advances in Engineering Software., 60-61: 89-97.

Song, W., Huang, B., Shu, X., et al, 2019. Interaction between Railroad Ballast and Sleeper: A DEM-FEM Approach. International Journal of Geomechanics, 19(5): 04019030.1-04019030.10.

Xiao, J., Wang, Y., Zhang, D., et al, 2020. Testing of Contact Stress at Ballast Bed-Soil Subgrade Interface under Cyclic Loading Using the Thin-Film Pressure Sensor. Journal of Testing and Evaluation, 48 (3): 20190171.

Xiao, J., Zhang, X., Zhang, D., et al, 2020. Morphological reconstruction method of irregular shaped ballast particles and application in numerical simulation of ballasted track. Transportation Geotechnics, 100374

Yan, P., Zhang, J., Fang, Q., et al, 2016. 3D numerical modelling of solid particles with randomness in shape considering convexity and concavity. Powder Technology, 301: 131-140.

Zhao, S., Zhou, X, 2017. Effects of particle asphericity on the macro- and micro-mechanical behaviors of granular assemblies. Granular Matter, 19(2): 38.

Zhang, Q., 2005. Dynamic Stress Analysis on Speed-increase Subgrade of Existing Railway. China Railway Science, 026(005): 1-5. 